\section{AMAMENTAÇÃO DO BEBÊ PREMATURO: UM RELATO DE EXPERIÊNCIA}

\section{PREMATURE BABY BREASTFEEDING: A REPORT OF EXPERIENCE}

Daiane de Carvalho Souza ${ }^{1}$ Ivanete Fernandes do Prado $1 /$ Midiã Ferreira dos Santos ${ }^{1, *} /$ Mônica Aparecida de Jesus ${ }^{1}$ / Mônica Silveira Matos ${ }^{1}$ / Romíria Brito dos Santos

\section{INTRODUÇÃO}

O nascimento prematuro ocorre quando o bebê nasce antes da $37^{\text {a }}$ semana de gestação e configura-se como um grave problema de saúde pública no Brasil, pois, além dos seus problemas inerentes a prematuridade pode trazer ao prematuro, complicações a longo prazo (MIRRA, 2017).

$\mathrm{O}$ bebê prematuro nasce com imaturidade dos seus órgãos e sistemas, o que o torna mais vulnerável a algumas doenças, mais sensível a determinados fatores externos, apresentando risco de vir a ter problemas no seu crescimento e desenvolvimento. Dessa forma diversas estratégias têm sido elaboradas na tentativa de auxiliar na prevenção, promoção e redução de doenças e agravos, assim como na diminuição das taxas mortalidade desse grupo populacional (MIRRA,2017; WALTY, DUARTE, 2017).

O prematuro necessita de inúmeros cuidados, dentre eles o aleitamento materno. $\mathrm{O}$ primeiro leite produzido pela mãe é chamado de colostro, sendo a alimento que criança precisa nos primeiros dias de vida, uma vez que é bastante nutritivo e com quantidade suficiente de substâncias que protege o bebê contra doenças e alergias. O leite materno é rico em proteínas gorduras e carboidratos, sendo assim importante fonte de nutrição para o lactente e é considerado um dos fatores fundamentais para a redução da morbimortalidade materno-infantil. (COSTA et al.,2013).

A amamentação supre todas as necessidades dos bebês, promove proteção e é essencial para o crescimento e desenvolvimento nos primeiros meses de vida. Este processo envolve interação profunda entre mãe e filho, com repercussões no estado nutricional da criança, em sua habilidade de se defender de infecções, em sua fisiologia, no seu desenvolvimento cognitivo e emocional, e em sua saúde a longo prazo, além de ter implicações na saúde física e psíquica da mãe (BRASIL, 2015; MOIMAZ et al., 2011).

\section{RESUMO}

O presente artigo teve como objetivo relatar a experiência vivenciada pelas monitoras e docente em ações de educação em saúde para um grupo de mães, sobre a importância da amamentação para o bebê prematuro. Trata-se de um relato de experiência, elaborado com base na intervenção de um projeto de pesquisa e extensão intitulado de Atividades Lúdicas e Educativas para Mães de Prematuros. As participantes do grupo foram mães de prematuros que estavam acolhidas em uma sala conhecida como alojamento mãe canguru de um hospital público do interior da Bahia. Realizou-se uma roda de conversa no qual foi discutido sobre a importância de amamentar o bebê exclusivamente com leite materno até os seus seis meses de vida, os benefícios do aleitamento materno, as dificuldades do prematuro para sugar a mama, a posição ideal para amamentar, a importância de colocar o bebê para arrotar e o que dever ser feito se o prematuro engasgar. A atividade realizada teve participação unânime das mães de prematuros que estavam internados na unidade neonatal no momento e muitas delas esclareceram dúvidas sobre a temática.

Palavras-chave: Aleitamento materno. Engasgo. Educação em saúde.

\section{ABSTRACT}

This article aimed to report the experience of the monitors and teacher in health education actions for a group of mothers, about the importance of breastfeeding for the premature baby.bThis is an experience report, prepared based on the intervention of a research and extension project entitled Playful and Educational Activities for Mothers of Premature Children. The group participants were mothers of preterm infants who were housed in a room known as kangaroo mother accommodation in a public hospital in the interior of Bahia. A conversation was held in which the importance of breastfeeding the baby exclusively with breast milk until the age of six months was discussed, the benefits of breastfeeding, the difficulties of the premature to suck the breast, the ideal position for breastfeeding, the importance of burping the baby and what should be done if the preterm chokes. The activity carried out had the unanimous participation of mothers of premature infants who were hospitalized at the neonatal unit at the time and many of them clarified doubts about the theme.

Keywords: Breastfeeding. Choking. Health education.

Submetido em: 08 de nov. 2019

Aceito em: 14 de fev. 2020

${ }^{1}$ Universidade do Estado da Bahia - UNEB, Guanambi, Bahia - Brasil.

*E-mail para correspondência: midiasantosf@gmail.com

Rev. ComCiência - jun. 2020, vol. 5, no. 6, p. 66-69/ doi: 10.36112/ issn2595-1890.v5.i6.p66-69 
A amamentação do bebê prematuro é uma a tarefa complexa visto que os mesmos apresentam um conjunto de fatores que os limitam, como imaturidade fisiológica e neurológica e falta de adequação de sucção, deglutição e respiração. Contudo, alimentá-lo com leite da própria mãe é a melhor opção, mas devido ao seu frágil desenvolvimento não será possível amamenta-lo no seio inicialmente, mas sim por sonda oro gástrica, com leite ordenhado da própria mãe, e com a evolução passa para o copinho e depois para o seio da mãe. Assim, faz-se necessário uma boa orientação sobre os cuidados e técnicas corretas para ordenha (GORGULHO,2008).

Segundo estudo feito por Alves (2018) descreve que mães que receberam orientações sobre a importância da amamentação nos primeiros meses de vida, pega correta e liberdade para livre demanda apresentaram uma maior prevalência de aleitamento materno enquanto que a menor prevalência ocorreu em mães com estilos de vidas relacionadas ao fumo e ao consumo excessivo de bebidas alcoólicas.

Para Almeida (2015) a redução do aleitamento materno pode ser promovida por uma falha de orientação, uma vez que os profissionais de saúde não estão cordialmente habilitados para fornecer informações de incentivo e promoção da amamentação. Sendo assim, é de grande relevância a preparação da equipe de profissionais de saúde e de implementações de ações educacionais preventivas para gestantes durante o pré-natal e após o parto (MOIMAZ et al,2011).

$\mathrm{O}$ incentivo, o apoio e orientações da equipe de profissionais da unidade neonatal no processo da amamentação é muito importante. Deve salientar as mães também sobre os benefícios da amamentação natural e adequar as funções de sucção deglutição e respiração para que o prematuro inicie a amamentação e que ocorra de forma prazerosa entre mãe e filho (GORGULHO, 2008; SOARES et al, 2016).

Diante exposto, o objetivo deste artigo é relatar a experiência vivenciada pelas monitoras e docente em ações de educação em saúde para um grupo de mães, sobre a importância da amamentação para o bebê prematuro.

\section{MATERIAIS E MÉTODOS}

Trata-se de um relato de experiência sobre a intervenção realizada pelas monitoras e docente do curso de enfermagem da Universidade do Estado da Bahia - Campus XII que atuam junto ao projeto de extensão e pesquisa intitulado "atividades lúdicas e educativas para mães de prematuros". Antes da realização da intervenção as monitoras foram previamente preparadas na instituição de ensino, através de estudos sobre o tema em questão, juntamente com a docente coordenadora.

Participaram do grupo, as mães dos recém-nascidos prematuros que estavam alojadas na unidade canguru no dia da intervenção para acompanhar e amamentar seus filhos e que se mostraram dispostas a participarem da ação educativa do projeto. A faixa etária das participantes variou de 14 a 39 anos.

O método da abordagem das mães foi através de "Roda de Conversa" conduzida pelas Monitoras e Coordenadora do Projeto da Universidade Estadual da Bahia. As mães de prematuros foram convidadas para irem ao auditório, local onde foi discutido o tema: Amamentação e engasgo do bebê. Concomitantemente as mulheres participaram com seus saberes e vivências prévias sobre o tema, gerando um momento importante para a troca de saberes e conhecimento.

Por se tratar de um relato de experiência não foi necessário a submissão ao Comitê de Ética em Pesquisa, mas foram tomados todos os cuidados referentes a um trabalho com seres humanos.

\section{RESULTADOS E DISCUSSÃO}

Inicialmente foi discutido pelas monitoras sobre a importância de amamentar o bebê exclusivamente com leite materno até os seus seis meses de vida, enfatizando que esse alimento não deve ser substituído por nenhum outro, pois além do leite materno conter proteínas e vitaminas, possui inúmeros fatores imunológicos que protegem a criança contra infecções.

De acordo com Silva e Guedes (2013) O leite materno é um alimento completo que dá nutrição, proteção contra doenças infecciosas, ajuda na oclusão dos dentes, diminui problemas na fala da criança e promove maior crescimento e desenvolvimento infantil. Além de benefícios nutricionais a amamentação promove benefícios emocionais, econômicos e estímulos neurais. Em prematuros o aleitamento materno resulta em maior inteligência, acuidade visual e menor falência por problemas respiratórios.

No decorrer da atividade educativa as mães demostraram conhecimento e interesse pela temática abordada, reconhecendo que ao amamentar estão favorecendo vínculos, fortalecendo o relacionamento afetivo e promovendo proteção ao prematuro. Ainda relataram que também são beneficiadas, pois o aleitamento contribui com a diminuição do sangramento pósparto. 
A amamentação apresenta benefícios tanto ao bebê quanto para a mãe. $\mathrm{O}$ aleitamento aumenta os laços afetivos por que ao procurar a mãe para saciar a fome o bebê recebe além de alimento, amor e afeto (GORGULHO, 2008), previne a anemia e faz com que o útero contraia e volte rápido ao tamanho normal, atuando ainda como um método de planejamento familiar. Estudos apontam que quanto mais a mulher amamenta menores são os riscos de desenvolver câncer de mama e ovários, além de tudo é econômico e prático não sendo necessário comprar leite artificial e demais fórmulas, (SILVA, GUEDES, 2013).

Os recém-nascidos prematuros apresentam certas dificuldades para dar início a amamentação, essas dificuldades podem ocorrer devido a inadaptação do recém-nascido como ausência de sucção dificuldade na pega e condições do recém-nascido, questões particulares da nutriz como insegurança ou medo para amamentar, posicionamento do bebê, falta de orientações ou características anatômicas dos mamilos como trauma mamilar, dores mamária, falta de preparo do mamilo, dor na ordenha, leite ralo e manutenção da lactação (SOARES et al.,2016).

Para os bebês que não consegue sugar pela dificuldade no desenvolvimento é muito importante a realização da ordenha em horários e de forma adequada. Mesmo que o bebê não esteja mamando a ordenha é importante, porque estimula a produção láctea posteriormente. A mãe pode sentir tensa ou nervosa por não conseguir realizá-la então é necessário que tenha a ajuda de um profissional até consegui-la (GORGULHO, 2008).

As mães receberam instruções indispensáveis para fazer ordenha. Ao realizar a ordenha é necessário que a mãe prenda os cabelos, use touca, proteja a boca e o nariz e lave bem as mãos, deve-se escolher um lugar limpo e calmo, com tranquilidade para permitir melhor facilidade e práticas adequadas. Prepare um frasco de preferência com tampa plástica fervido por 15 minutos e comece a massagear o peito com as pontas dos dedos iniciando na região mais próxima da aréola para mais distante e apoiar a ponta dos dedos polegar e indicador acima e abaixo da aréola comprimindo o peito contra o tórax com movimentos rítmicos. Desprezar os primeiros jatos e guardar o restante.

O leite ordenhado deve ser guardado em recipientes limpos de tampa plástica em local limpo na geladeira. O leite pode ser refrigerado por 24 horas ou congelado por 15 dias. Antes de alimentar o bebê com leite guardado, aqueça em banho-maria ou na temperatura ambiente e ofereça no copinho. Para isso deve-se lavar as mãos, observar a temperatura do leite, colocar o bebê semi sentado e apoiar a borda do copo no lábio superior do bebê para evitar que empurre o copo para fora com a língua e esperar que o bebê sova o leite e não forçar obrigando-o a engolir (FONSECA; SCOCHI, 2009).

Comparado às outras crianças, os bebês prematuros apresentam maiores necessidades calóricas para seu rápido crescimento e desenvolvimento por isso, as mamadas devem ocorrer sob livre demanda variando entre 8 a 10 mamadas diárias para estimulação da prolactina e consequentemente a maior produção láctea (SILVA, 2009).

As monitoras explicaram a importância de colocar o bebê na posição correta para que ele consiga pegar a mama. A mãe pode escolher uma posição deitada, sentada ou em pé o importante é que ambos se sintam confortáveis. O corpo do bebê deve aproximar- se da mãe e a boca do bebê deve ficar na mesma posição da aréola. O bebê deve ficar de frente para a mãe bem alinhado, e a mãe pode posicionar a criança no mamilo apoiando o braço e a mão ao corpo e ao bumbum do bebê e fazer com que ele estimule o reflexo da procura e busque o peito abocanhando a maior parte da aréola evitando fissuras e a mãe pode sentir a sucção e a deglutição da mamada.

Ao dar de mamar, a mãe deve estar calma e não apressar o bebê. Se o peito estiver muito cheio é necessário que faça uma ordenha manual, assim a aréola ficará mais macia. A mãe deve oferecer ambos os peitos desde a sala de parto sob livre demanda, se o bebê desejar, até ele soltar.

Após as mamadas deve se colocar o bebê para arrotar. Deve-se levantá-lo, apoiar a cabeça no seu ombro e fazer uma leve massagem nas costas ou colocar sentado no colo da mãe inclinado para frente, apoiado com os braços da mãe voltado para frente com as pernas flexionadas e movimentá-lo o mínimo possível, para evitar regurgitação e engasgo.

Uma das mães questionou o motivo de colocar o bebê pra arrotar e quais as consequências teriam se não o pusesse. Á visto disso, foi abordado o tema seguinte da intervenção. As monitoras deram continuidade na atividade educativa explicando sobre o que fazer se o bebê engasgar e como diferenciar o engasgo parcial do total. Para isso utilizou-se recurso visual simulando a via respiratória para melhor compreensão da temática. Quando o bebê está chorando, ofegante e respirando rápido, agitado ou tossindo, ele pode está tendo um engasgo parcial. Nesse momento a mãe, deve manter a calma, segurar o bebê no seu colo em posição confortável virado em sua direção. 
Porém, se bebê não consegue, tossir ou chorar, os lábios do bebê estão arroxeados ou sem conseguir respirar, ele provavelmente está tendo um engasgo total. Com isso, é importante manter a calma, chamar socorro, e tentar reanimá-lo. Coloque o bebê em decúbito ventral em cima do seu antebraço, com a cabeça mais baixa que o corpo e apoie seu antebraço na sua coxa para ter mais firmeza, mantenha a boca do bebê aberta, segurando-a com o dedo indicador e médio, dê 5 tapas com a base da mão entre os ombros, no meio das costas do bebê. Reposicione o bebê em decúbito dorsal sobre o outro antebraço apoiado sobre a coxa e verifique se desengasgou. Caso continue engasgado, iniciar a massagem cardíaca, realizando 5 compressões com dois dedos no meio do peito, entre os mamilos. É recomendado que cada compressão deve ter 4 centímetros 2 a 3 dedos de profundidade.

Por fim as mães relataram sobre suas vivências quanto ao engasgo e muitas disseram que ao enfrentarem essa situação, não souberam como agir. Algumas comentaram ficarem apreensivas e inseguras.

A atividade realizada teve participação unânime das mães dos prematuros internados na unidade neonatal e muitas das presentes esclareceram dúvidas sobre a temática. Os resultados superaram as expectativas, tendo em vista que foi imaginado que o tema era conhecido, porém, muitos dos conceitos e situações foram desmitificados ao longo das discussões geradas.

\section{CONCLUSÃO}

Partindo do pressuposto de que o aleitamento materno é essencial para o desenvolvimento infantil, é de grande importância a realização de ações educativas para promoção do aleitamento materno.

Através desta atividade educativa do projeto pode-se perceber que as mães se mostraram interessadas e muito participativas, buscaram sanar suas dúvidas em relação a amamentação e cuidados a serem realizados quando o bebê engasgar.

A formação de grupos de apoio favorecem uma interação e diálogo com a comunidade aprimorando o conhecimento e promovendo a interligação da teoria à prática.

\section{REFERÊNCIAS}

ALMEIDA, Jordana Moreira de; LUZ, Sylvana de Araújo Barros; UED, Fábio da Veiga. Apoio ao aleitamento materno pelos profissionais de saúde: revisão integrativa da literatura. Rev. paul. pediatr., São Paulo, v. 33, n. 3, p. 355-362. 2015.

ALVES, Jessica de Souza; OLIVEIRA, Maria Inês Couto de; RITO, Rosane Valéria Viana Fonseca. Orientações sobre amamentação na atenção básica de saúde e associação com o aleitamento materno exclusivo. Ciênc. saúde coletiva, Rio de Janeiro, v. 23, n. 4, p. 1077-1088, 2018.

COSTA,Luhana Karoliny Oliveira et al. Importância do aleitamento materno exclusivo: uma revisão sistemática da literatura. Rev. Ciên. Saúde. v. 15, n. 1, 2013.

GORGULHO, Fernanda da Rocha; PACHECO, Sandra Teixeira de Araújo. Amamentação de prematuros em uma unidade neonatal: a vivência materna. Esc. Anna Nery, Rio de Janeiro , v. 12, n. 1, p. 19-24, 2008.

MOIMAZ, Suzely Adas Saliba et al . Relação entre aleitamento materno e hábitos de sucção não nutritivos. Ciênc. saúde coletiva, Rio de Janeiro , v. 16, n. 5, p. 2477-2484, 2011 .
RIGOTTI, Renata Ribeiro; OLIVEIRA, Maria Inês Couto de; BOCCOLINI, Cristiano Siqueira. Associação entre o uso de mamadeira e de chupeta e a ausência de amamentação no segundo semestre de vida. Ciênc. saúde coletiva, Rio de Janeiro , v. 20, n. 4, p. $1235-1244,2015$.

SOARES, Jeyse Polliane de Oliveira et al . Amamentação natural de recémnascidos pré-termo sob a ótica materna: uma revisão integrativa. Rev. CEFAC, São Paulo, v. 18, n. 1, p. 232241, 2016.

SILVA, Rosangela Venancio da; SILVA, Isília Aparecida.A vivência de mães de recém-nascidos prematuros no processo de lactação e amamentação.Esc. Anna Nery Rev. Enferm,v.13,n.1,p.108-115, 2009.

SILVA, Waléria Ferreira da; GUEDES, Zelita Caldeira Ferreira. Tempo de aleitamento materno exclusivo em recém-nascidos prematuros e a termo. Rev. CEFAC, São Paulo, v. 15, n. 1, p. 160-171, 2013. 